\title{
Identifying the Determinants of Michinoeki Performance
}

\author{
Takao Ito ${ }^{1}$, Tsutomu Ito ${ }^{2,}$, Seigo Matsuno ${ }^{2}$, Rajiv Mehta ${ }^{3}$, Makoto Sakamoto ${ }^{4}$ \\ ${ }^{1}$ Graduate School of Advanced Science and Engineering, Hiroshima University, 1-4-1 Kagamiyama, Higashi Hiroshima 739-7527, Japan \\ ${ }^{2}$ Department of Business Administration, National Institute of Technology, Ube College, 2-14-1, Tokiwadai, Ube City, Yamaguchi Pref. 755-8555, Japan \\ ${ }^{3}$ Martin Tuchman School of Management, New Jersey Institute of Technology, Newark, NJ 07102-1982, USA \\ ${ }^{4}$ Faculty of Engineering, University of Miyazaki, Miyazaki-City, Miyazaki 889-2192, Japan
}

\section{ARTICLE INFO \\ Article History \\ Received 01 October 2018 \\ Accepted 22 June 2021 \\ Keywords \\ Michinoeki \\ revitalization \\ sales revenue \\ number of purchasers}

\begin{abstract}
Widely recognized as providing vital services in the transportation sector, it is important to identify the determinants as well as estimate their impact on Michinoeki today. Seemingly, no research has studied their influence using data on all the 1107 Michinoeki established as of April 2017. To attain a better understanding, Japan was divided into nine areas to detect regional differences in the determinants of Michinoeki. The findings of the study indicate that, as expected, there are wide regional variations in the key characteristics of Michinoeki. This paper makes a contribution to the knowledge by: (1) Understanding the status quo of Michinoeki and (2) Identifying important salient factors for their further development. Based on the results, the administrative implications are identified, the research limitations are discussed and avenues for further research are proffered.
\end{abstract}

(C) 2021 The Authors. Published by Atlantis Press International B.V. This is an open access article distributed under the CC BY-NC 4.0 license (http://creativecommons.org/licenses/by-nc/4.0/).

\section{INTRODUCTION}

Michinoeki have widely been acknowledged as an important model for revitalization of Japan's regional economies. Maryvonne observed that "Michinoeki can be an effective tool for attenuating poverty because they address social issues and benefit local residents directly" [1]. Although Michinoeki originated and became pervasive in Japan, they have also spread to Kenya and China. Seemingly, no research has been undertaken to identify their key determinants nor estimate the impact of Michinoeki using the complete data set of all 1107 such transportations hubs established as of April 2017. Using data drawn from the complete population of 1107 Michinoeki, this investigation attempts to shed light on identifying the salient characteristics these transportation hubs, so that important insights can be attained that provide guidance for improving the efficiency, effectiveness as well as augmenting the quality of management.

This paper is structured as follows: Section 2 introduces the background of this research. In Section 3, the paper explicates data collection and multivariate regression model using specific 18 variables selected from the data set of whole Japan. Section 4 shows the results and discussions on our findings. The conclusions and directions for further research and managerial implications are proffered in the final section.

\section{BACKGROUND}

Michinoeki are located along major national highways with four functions of (1) providing free parking space, restrooms,

"Corresponding author.Email: t_ito@ube-k.ac.jp
(2) spreading information, (3) allying with regional society, and (4) preventing disaster. Accordingly, the four-function model of Michinoeki could be illustrated in Figure 1.

Numerous theories and analyses of Michinoeki rooted in the four viewpoints have been published. For instance, research by Sakamoto and Toda examined the relationship between communication of tourist information from Michinoeki and regional revitalization based on the viewpoint of local tourist policy [2]. Kumano et al. [3] identified successful determinants of Michinoeki in Chugoku area using regression modelling. Hiraoka et al. [4] investigated the linkage between the number of customers and information associated with agriculture, forestry, and fisheries in the vicinity of Michinoeki. In addition, Kumano et al. [5] identified the antecedents of Michinoeki in the Kyushu area. Recently Ito et al. [6] proposed a new approach to calculate the efficiency of the Michinoeki in Yamaguchi area using Data Envelopment Analysis (DEA) model after determining the significant factors using a regression model. Seemingly, no investigations have estimated the characteristics of all 1107 Michinoeki established as of April 2017 in aggregate form. To identify the salient factors of Michinoeki, this study divided Japan into nine areas that include: Chubu, Chugoku, Kanto, Hokkaido, Hokuriku, Kinki, Kyushu/Okinawa, Shikoku, and Tohoku. Eighteen factors (subsequently discussed) were selected from the database to ascertain the key antecedents of Michinoeki in each of the nine regions.

\section{DATA COLLECTIONS AND MODEL BUILDING}

Data from 2015 were drawn from the internal databases of Michinoeki headquarters. The 18 variables selected as the determinants express the four critical functions in Michinoeki, which 


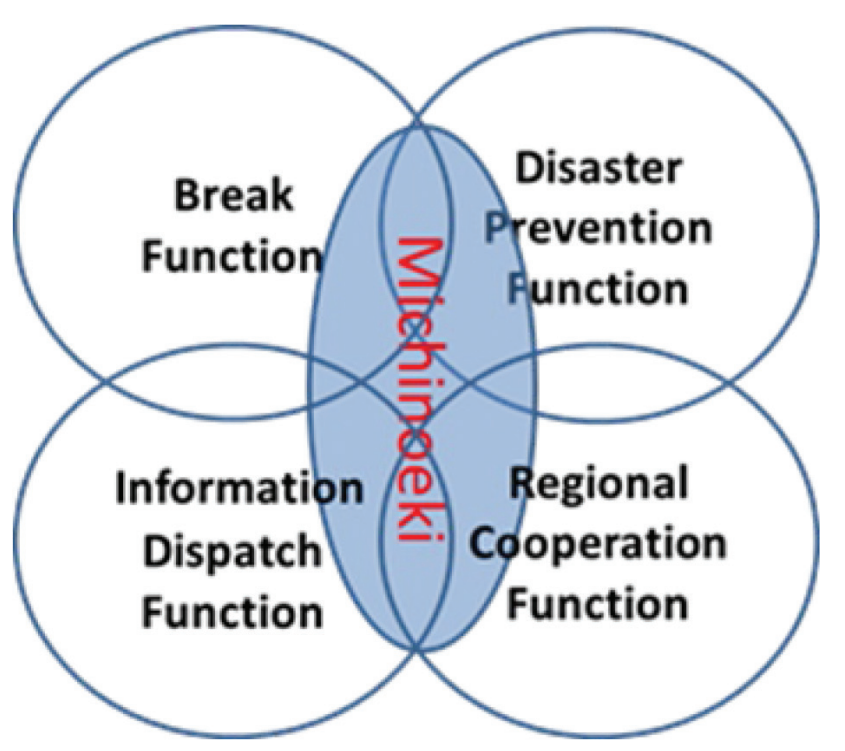

Figure 1 Four-function conceptual model of Michinoeki.

include: (1) Square Meters of Land Space (SMLS), (2) Number of Standard-Sized Car Parking Lot (NSSCPL), (3) Number of Large Vehicles (NLV), (4) Square Meters of Parking Area (SMPA), (5) Total Number of the Restroom (TNR), (6) Square Meters of Free Rest Place (SMFRP), (7) Total Seats of the Free Rest Place (TSFRP), (8) Weekdays' Traffic Near the Station (WTNS), (9) Holidays' Traffic Near the Station (HTNS), (10) Population of the City Located (PCL), (11) Operating Cost (OC), (12) Number of the Agriculture and Marine Products (NAP), (13) Number of the Local Products (NLP), (14) Number of the Selling Items (NSI), (15) Number of Original Products (NOP), (16) Number of the Registered Farmers (NRF), (17) Square Meters of the Facilities for Marine Products (SMFMP), and (18) Square Meters of Facilities Space (SMFS). SMLS, SMPA, SMFAP, SMFS, and OC collectively serve the function of spreading information and disaster prevention. NSSC, NLV, TNR, SMFPR, TSFRP, WTNS, and HTNS are viewed as indicants of providing free parking space and restrooms. PCL, NAP, NLP, NSI, NOP, and NRF in concert play an important role in building alliances and fostering close relationships with regional society. Sales revenue and number of purchasers are selected as performance indicators of Michinoeki. Thus, this leads to the formation of the following multivariate regression equation (1):

$$
\begin{aligned}
y= & a 1 \text { SMLS }+a 2 \mathrm{NSSC}+a 3 \mathrm{NLV}+a 4 \mathrm{SMPA}+ \\
& a 5 \mathrm{TNR}+a 6 \mathrm{SMFRP}+\mathrm{a} 7 \mathrm{TSFRP}+a 8 \mathrm{WTNS}+ \\
& a 9 \mathrm{HTNS}+a 10 \mathrm{PCL}+a 11 \mathrm{OC}+a 12 \mathrm{NAP}+ \\
& \text { a13NLP }+a 14 \mathrm{NSI}+a 15 \mathrm{NOP}+a 16 \mathrm{NRF}+ \\
& a 17 \mathrm{SMFAP}+a 18 \mathrm{SMFS}+\varepsilon
\end{aligned}
$$

\section{CALCULATION AND DISCUSSION}

The standardized correlation coefficients between the 18 variables and sales revenue and number of purchasers are calculated respectively. The results are shown as in Tables 1 and 2.

First, the correlation coefficients of (1) SMLS are all negative. The possible reason is that the large size of Michinoeki is to provide free space for visitors. Second, the correlation coefficients of (17) SMFMP, and (18) SMFS are all positive. Thus, the size of marine

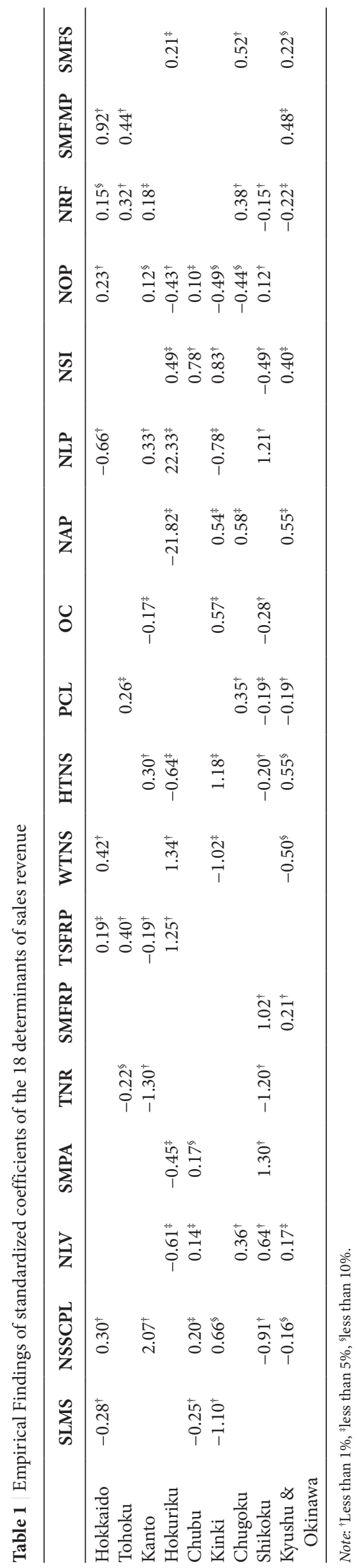




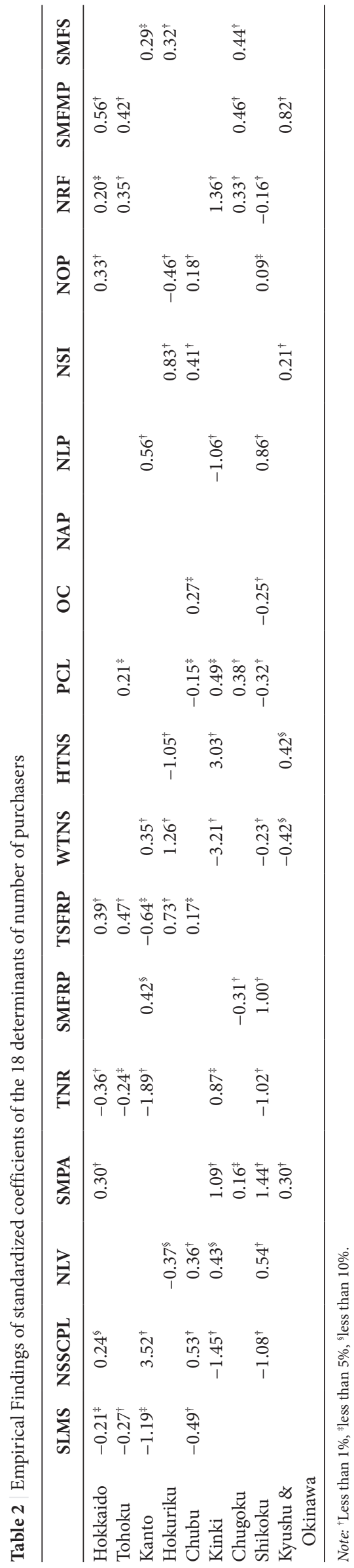

Table 3 Key determinants of Michinoeki by region

\begin{tabular}{|c|c|c|}
\hline \multirow{2}{*}{$\begin{array}{l}\text { Area } \\
\text { Hokkaido }\end{array}$} & \multicolumn{2}{|c|}{ Key determinants } \\
\hline & $\begin{array}{l}\text { Square meters of the } \\
\text { facilities for marine } \\
\text { products (SMFMP) }\end{array}$ & $\begin{array}{r}\text { Weekdays' traffic near } \\
\text { the station (WTNS) }\end{array}$ \\
\hline Tohoku & $\begin{array}{l}\text { Square meters of the } \\
\text { facilities for marine } \\
\text { products (SMFMP) }\end{array}$ & $\begin{array}{l}\text { Total seats of the free } \\
\text { rest place (TSFRP) }\end{array}$ \\
\hline Kanto & $\begin{array}{l}\text { Number of standard- } \\
\text { sized car parking lot } \\
\text { (NSSCPL) }\end{array}$ & \\
\hline Hokuriku & $\begin{array}{l}\text { Number of the local } \\
\text { products (NLP) }\end{array}$ & \\
\hline Chubu & $\begin{array}{l}\text { Number of the selling } \\
\text { items (NSI) }\end{array}$ & \\
\hline Kinki & $\begin{array}{l}\text { Holidays' traffic near } \\
\text { the station (HTNS) }\end{array}$ & \\
\hline Chugoku & $\begin{array}{l}\text { Number of the agriculture } \\
\text { and marine products (NAP) }\end{array}$ & $\begin{array}{l}\text { Square meters of } \\
\text { facilities space (SMFS) }\end{array}$ \\
\hline Shikoku & $\begin{array}{l}\text { Square meters of parking } \\
\text { area (SMPA) }\end{array}$ & $\begin{array}{l}\text { Number of the local } \\
\text { products (NLP) }\end{array}$ \\
\hline $\begin{array}{l}\text { Kyushu and } \\
\text { Okinawa }\end{array}$ & $\begin{array}{l}\text { Number of the agriculture } \\
\text { and marine products (NAP) }\end{array}$ & $\begin{array}{l}\text { Holidays' traffic near } \\
\text { the station (HTNS) }\end{array}$ \\
\hline
\end{tabular}

product retailers and the larger scale of the facilities contributes both to increase sales revenues as well as the number of purchasers. Third, (17) SMFMP has strong impact on the performance for the Hokkaido, Tohoku, and Kyushu/Okinawa. Interestingly, the results reveal that Kyushu/Okinawa have a pronounced effect by (17) SMFMP, and (9) HTNS. Thus, this indicates that performance is effected by both SMFMP and HTNS, which differs from Hokkaido and Tohoku. Fourth, the highest value for the Kanto region is (2) NSSCPL. This indicates that traffic is considered a key determinant in the Kanto region. Fifth, the key determinants of Hokuriku, Chubu, Chugoku, and Kinki are (13) NLP, (14) NSI, (12) NAP, and (9) HTNS. Kanto and Shikoku are effected by (4) SMPA, (2) NSSCPL, and NLP. These findings reveal that the key determinants for different regions are divergent in their characteristics. Taken together, the key antecedents of each regional area are summarized in Table 3.

\section{CONCLUSION}

The statistical findings of the linkages among the 18 factors as predictors of sales revenues and number of purchasers were estimated using multiple regression modelling. Evidently, the key determinants are divergent for each regional area. For example, sales revenues of Hokkaido, Tohoku, and Kyushu/Okinawa regions are primarily dependent on the square meter size of the facilities for marine products, but the influence of Tohoku is weaker than Hokkaido, and Kyushu/Okinawa, which are seemingly affected by the square meter size of the facilities for agriculture products as well as HTNS.

Firm conclusions should not be made given the exploratory nature of the study; thus, some caution is suggested. Consequently, additional replication of this investigation is warranted to find conclusive support for the preliminary results. As findings based on one fiscal year data set is not sufficient, additional avenues for future research will be fruitful with longitudinal studies that 
might shed light if the divergent determinants of Michinoeki are temporal in nature.

\section{CONFLICTS OF INTEREST}

The authors declare they have no conflicts of interest.

\section{REFERENCES}

[1] The World Bank, Guidelines for Roadside Stations "Michinoeki”, p. 7, retrieved June 2, 2021.

[2] S. Yasumasa, T. Kaori, Communication of Tourist Information from Michinoeki and Activation of Local Area, retrieved June 2, 2021.

\section{AUTHORS INTRODUCTION}

\section{Dr. Takao Ito}

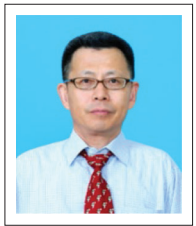

He is Professor of Management of Technology (MoT) in Graduate School of Engineering at Hiroshima University. $\mathrm{He}$ is serving concurrently as Professor of Harbin Institute of Technology (Weihai) China. He has published numerous papers in refereed journals and proceedings, particularly in the area of management science, and computer science. He has published more than eight academic books including a book on Network Organizations and Information (Japanese Edition). His current research interests include automata theory, artificial intelligence, systems control, quantitative analysis of inter-firm relationships using graph theory, and engineering approach of organizational structures using complex systems theory.
[3] M. Kumano, T. Ito, T. Ito, T. Hiraoka, H. Nonaka, M. Hirota, Discovering Successful Determinants of Efficiency of Michinoeki in Chugoku Area, Proceedings of The 2018 International Conference on Artificial Life and Robotics, B-Con Plaza, Beppu, Oita, Japan, 2018, pp. 352-354.

[4] T. Hiraoka, S. Nishimura, H. Nonaka, T. Ito, M. Kumano, A correlation analysis between information related to the number of customers and the agriculture, forestry, and fisheries of Michi-no-eki in Japan, J. Inst. Ind. Appl. Eng. 6 (2018), $173-178$

[5] M. Kumano, T. Ito, T. Ito, A determinants analysis of the Michinoeki in Japan, Int. J. Econ. Manage. Syst. 2 (2017), 287-291.

[6] T. Ito, M. Kumano, T. Ito, Measuring efficiencies of Michinoeki using DEA model in Yamaguchi area, J. Robot. Netw. Artif. Life 7 (2020), 204-207.

\section{Dr. Seigo Matsuno}

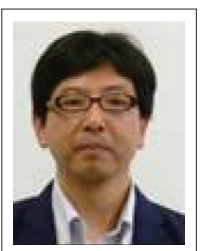

He is Professor of the Department of Business Administration at National Institute of Technology, Ube College, Japan. He received his $\mathrm{PhD}$ degree in Economics from Kyushu University, Japan in 2004. His current research interests are in the areas of IT management and strategy, information systems outsourcing, and interfirm relationship management. He has published several research papers and books in that area. He is a member of the Board of the Directors of Japan Society for Information and Management.

\section{Dr. Tsutomu Ito}

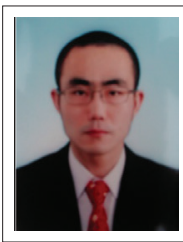

He is Assistant Professor of the Department of Business Administration at National Institute of Technology, Ube College, Japan. He has published many papers in refereed journals and proceedings, particularly in the area of industrial management, and computer science. His current research interests include internet of things (IoT), mechanical engineering, artificial intelligence (AI), automata theory, quantitative analysis of Japanese Keiretsu. He was one of the winners of the Best Paper Award in the International Conference on Artificial Life and Robotics (ICAROB) in 2015 and 2016. He earned his Doctor degree of Engineering from Hiroshima University, Japan in 2018.

\section{Dr. Rajiv Mehta}

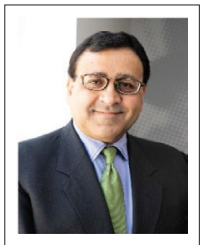

$\mathrm{He}(\mathrm{PhD}$, Drexel University) is Professor of Marketing at Martin Tuchman School of Management, New Jersey Institute of Technology, USA. Previously, he worked for an international manufacturer of steel cables. He has co-authored four university textbooks, including Sales Force Management, 2nd ed. (2020). Focusing on sales management, global marketing channels, Keiretsus, and international strategic alliances, his research is published in Sloan Management Review, Journal of Business Research, Industrial Marketing Management, European Journal of Marketing, International Marketing Review, and Artificial Life and Robotics, among others. 
Dr. Makoto Sakamoto

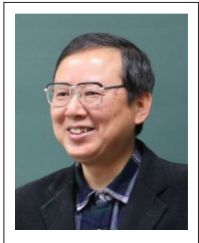

He received the $\mathrm{PhD}$ degree in computer science and systems engineering from Yamaguchi University. $\mathrm{He}$ is presently Professor in the Faculty of Engineering, University of Miyazaki. $\mathrm{He}$ is a theoretical computer scientist, and his current main research interests are automata theory, languages and computation. He is also interested in digital geometry, digital image processing, computer vision, computer graphics, virtual reality, augmented reality, entertainment computing, complex systems and so on. 